\title{
Adsorption of Cerium (IV) from Aqueous Solutions Using Activated Carbon Developed from Rice Straw
}

\author{
Ehsan Farahmand \\ Department of Mining Engineering, Science and Research Branch, Islamic Azad University, Tehran, Iran \\ Email: farahmand.ehsan@yahoo.com
}

Received 25 February 2016; accepted 26 March 2016; published 29 March 2016

Copyright (C) 2016 by author and Scientific Research Publishing Inc. This work is licensed under the Creative Commons Attribution International License (CC BY). http://creativecommons.org/licenses/by/4.0/ (c) (i) Open Access

\section{Abstract}

In this study, the adsorption of Cerium from synthetic solution containing cerium oxide is investigated using activated carbon developed from rice straw that is activated by $\mathrm{H}_{3} \mathrm{PO}_{4}$. SEM and FTIR techniques are used to examine structural and morphological characteristics of rice straw and activated carbon. The optimum conditions obtained with the highest adsorption include contact time $=500$ minutes, $\mathrm{pH}=4$, temperature $=35^{\circ} \mathrm{C}$, cerium concentration $=300 \mathrm{ppm}$, and adsorbent dosage $=0.02 \mathrm{gr}$. The highest adsorption of Cerium is determined by $4.13 \mathrm{mg} / \mathrm{g}$. Adsorption kinetics of cerium and equilibrium behavior is studied. It indicates that the adsorption process obeys Pseudo-first-order kinetic model and Langmuir isotherm model. The results of this study show that the activated carbon developed from rice straw activated by $\mathrm{H}_{3} \mathrm{PO}_{4}$ is a relatively effective adsorbent for the adsorption of cerium from aqueous solution.

\section{Keywords}

Activated Carbon, Cerium, Isotherms, Adsorption Kinetics, Temperature, pH

\section{Introduction}

In recent years, the separation and upgrading rare earth elements with an increased demand for these elements and their compounds are important. The most important uses of this element include controllers of nuclear reactors, production of radiopharmaceuticals, construction of petrochemical catalysts, colored glass, aluminum and steel industries, laser industry, glass that absorbs infrared wavelengths, refining crude oil, production of superconductors and super magnets, chips and computer hard disks, colored bulbs, etc. [1] [2].

Extraction and separation of lanthanides from each other due to their very similar physical and chemical 
properties are considered as a challenge. Thus, it is necessary to provide a method that makes the separation of their selection easy [3] [4]. Solvent extraction and ion exchange are the most important method of extraction and recovery of lanthanides. The use of the above methods is not cost-effective due to a series of technical limitations and high cost of organic solvents. Therefore, it is necessary to search for new methods and biosorption is considered as a new option in this regard [5].

Biosorption is process leading to the separation of metals from aquatic environment using biological materials such as bacteria, fungi, algae and agricultural waste through the creation of complex by toxic elements due to specific groups. The mechanism of biosorption is usually related to chemical bonding between groups of adsorbent surface and metal ions or ion exchange due to ion exchange capacity of the adsorbent. Forasmuch as this process is low-cost, eco-friendly and has a high performance adsorption, it is considered as an efficient alternative to traditional methods for eliminating toxic elements [6]. That is why in recent years the use of byproducts and agricultural waste such as bark of trees, sawdust, pistachio bark, almond shell, rice and wheat bran, corn residue, etc. have been developed due to cellulosic materials, carbon, and silica in their chemical structure to absorb rare earth elements from water and wastewater [7].

Biological materials are abundant are available on the one hand, and they are not used certainly on the other hand. Activated carbon as an adsorbent with high adsorption capacity and low price has many uses in the processes of adsorption from the liquid or gas phase. The production of activated carbon is possible using two methods of physical and chemical activation [8] [9]. The purpose of activation is creating a porous structure of carbon with high free in the raw material [10]. In this study, rice straw is used in a chemical activation method considered as a single-stage method for the production of activated carbon. Thus, raw material is mixed with a concentrated solution of an activating agent and the dried mixture is then heated in the oven in an inert atmosphere.

\section{Materials \& Methods}

Chemicals used in this study included cerium oxide, deionized water to prepare a solution containing rare earth elements, hydrochloric acid, ammonia to adjust pH from Merck Company, phosphoric acid 98\% - 100\%, and distilled water for dilution. Rice straw used in the study was prepared by the agricultural lands in Mazandaran province in the north of Iran. In order to prepare the adsorbent, rice straw was minced into an electric mill. Then it was rinsed with double distilled water and is kept in the oven at a temperature of $60^{\circ} \mathrm{C}$ to be dried completely.

First, the dried raw material was combined with a solution of phosphoric acid. Then, it was placed on a heater at $100^{\circ} \mathrm{C}$ and stirred to evaporate the moisture in the mixture of straw and phosphoric acid. Next, it was put into the oven at $150^{\circ} \mathrm{C}$ for 4 hours to be dried completely. After that, the obtained material was placed into a vacuum furnace at $500^{\circ} \mathrm{C}$ for 1 hour. The obtained adsorbent was rinsed with distilled water and then dried in the oven at $100^{\circ} \mathrm{C}$. Finally, the obtained activated carbon was screened using an ASTM E11sieve, 45 meshes (355 micron), to achieve dimensions of 500 - 250 microns.

Image of scanning electron microscope (SEM), a layer of raw straw and activated carbon, is shown in Figure 1. Figure 2 shows functional groups, their formed bonds, and its range for raw straw and activated carbon using Fourier Transform InfraRed (FTIR).

\subsection{Adsorption Studies}

Adsorption experiments were carried out in a batch system for determining $\mathrm{pH}$, the equilibrium time, optimum temperature, amount of adsorbent, the adsorption capacity of rare earth elements, determination of kinetic and isotherm model. In this research during the reaction time, the contents of the container includes a certain amount of adsorbent and $30 \mathrm{ml}$ serum concentration on a temperature controlled shaker with a mixing speed of $200 \mathrm{rpm}$. The Induction Coupled Plasma (ICP) device was used to measure the remaining elements in the solution and also determine the adsorption of Cerium in each experiment. After the reaction, the amount of adsorption was determined by calculating the difference between the initial and final concentration. The amount of Cerium adsorption was determined using the following formula:

$$
q_{e}=\frac{\left(C_{0}-C_{e}\right) v}{m}
$$

where $C_{0}$ is the initial concentration of Cerium (mg/l), $C_{e}$ is the concentration of Cerium at equilibrium (mg/l), $q_{e}$ is the amount of Cerium adsorption (mg/g), $m$ is the amount of adsorbent (gr), and $V$ is volume of the solution (l). 


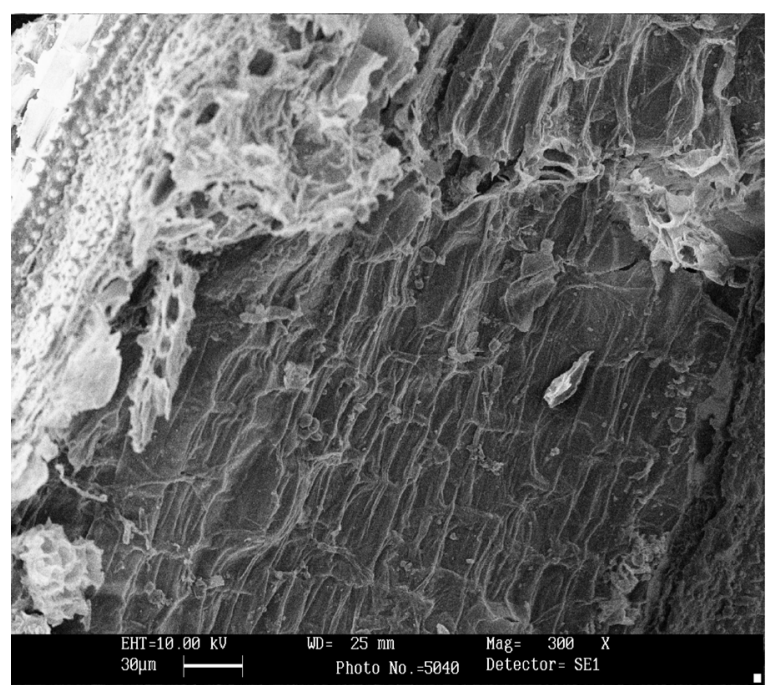

(a)

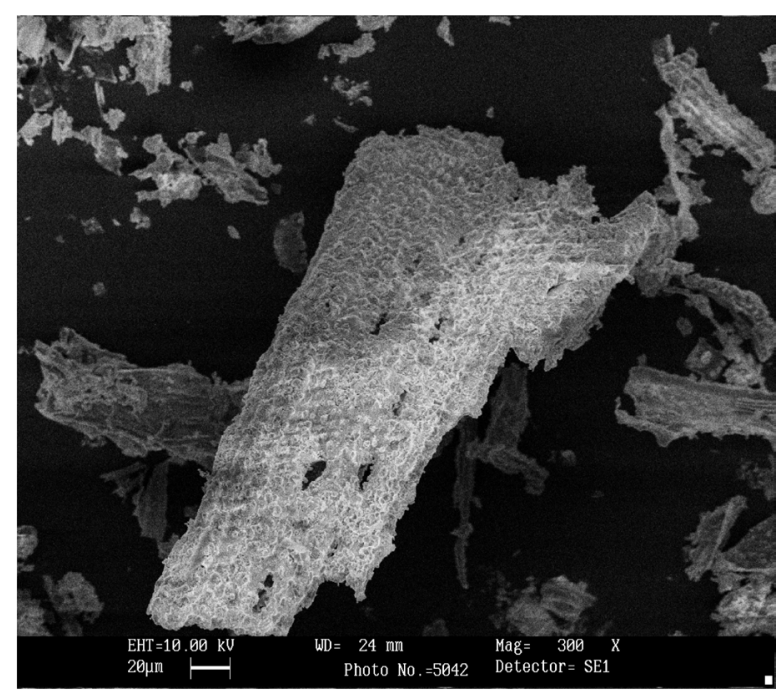

(b)

Figure 1. (a) SEM image of raw straw; (b) Activated carbon mixed with $\mathrm{H}_{3} \mathrm{PO}_{4}$.

\subsection{The Effects of Solution $\mathrm{pH}$}

Solution $\mathrm{pH}$ is an important factor for process control of biosorption and affects the characteristics of metal in solution during the reaction of hydrolysis, complexing and reducing the metal recovery [11]. The $\mathrm{pH}$ factor is capable of influencing the analysis status and the bond place. In addition, this factor is capable of affecting the desired metal solution in the form of hydrolysis and complexing through organic and inorganic ligands [12]. In this study, the $\mathrm{pH}$ of the aqueous solution was determined between 1 and 7. As shown in Figure 3, the highest adsorption of cerium is determined by $\mathrm{pH}=4$.

\subsection{The Effect of Temperature}

Temperature of the process is also an important factor influencing the biological adsorption of metal ions [13]. Experiments of cerium adsorption were studied at $20^{\circ} \mathrm{C}, 25^{\circ} \mathrm{C}, 30^{\circ} \mathrm{C}, 35^{\circ} \mathrm{C}$ and $40^{\circ} \mathrm{C}$. It was found that the temperature in the range $20^{\circ} \mathrm{C}$ to $35^{\circ} \mathrm{C}$ has no effect on the biosorption and the cerium adsorption is influenced by temperature at $35^{\circ} \mathrm{C}$ to $40^{\circ} \mathrm{C}$ (Figure 4).

\subsection{The Effect of Adsorbent Dosage}

The concentration of adsorbent has a large impact on the adsorbent dosage in a way that increasing the concentration of biosorbents usually decreases the adsorbent dosage which may be due to the complex performance of several factors. At high concentrations of adsorbent, there is not enough adsorbent for complete coverage of solutions with the ability for adsorption on biosorbents which usually leads to low loading of adsorbent. The interference between the bond places due to the high concentration of biosorbents will reduce the loading capacity [14] [15]. Figure 5 shows the effect of adsorbent dosage on cerium adsorption.

\subsection{The Effects of Initial Concentration of Metal}

Biosorption of cerium was studied as a function of metal concentration in the range of 50 to $300 \mathrm{mg} / \mathrm{L}$. The amount of cerium adsorbed onto activated carbon increases with increasing initial concentration of metal ions. For element of cerium, when the ion concentration increases, the equilibrium loading of metal ion significantly increases and there is often saturation at higher concentrations (Figure 6).

\subsection{The Effect of Contact Time}

As shown in Figure 7, the capacity of cerium adsorption is high in the first 300 minutes and increases with increasing contact to 500 minutes. After that, there is no significant increase in cerium adsorption. So, this time of 
interaction can be considered as equilibrium time of reaction. Rapid adsorption in the initial stages is probably due to the increase in the concentration gradient between the adsorbed material in the solution and adsorbent. As long as the phenomenon of adsorption desires to achieve a stable equilibrium, the initial rapid loading of metal ion will be in the form of physical adsorption. When the contact time increases, many operating groups will par-

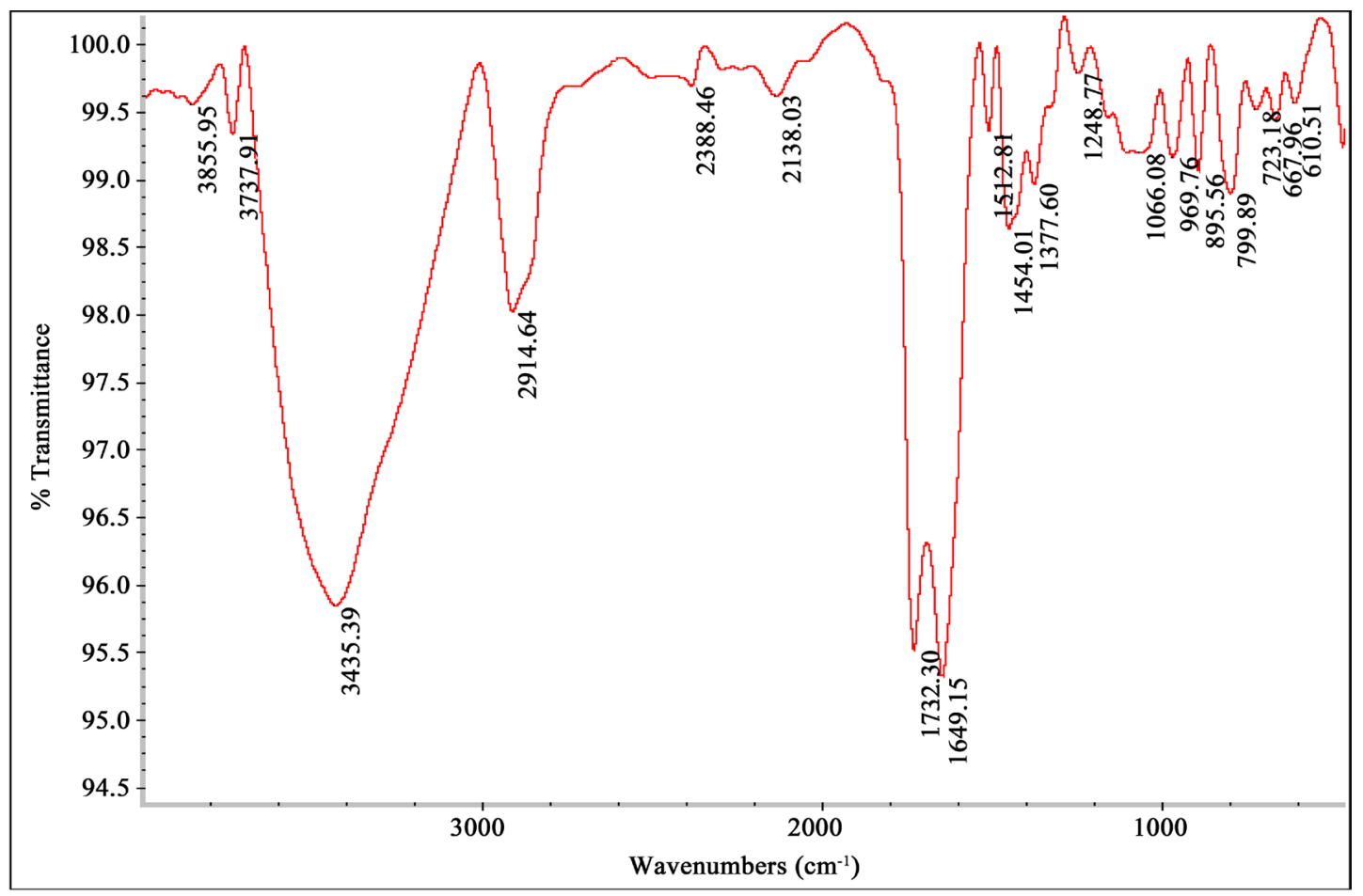

(a)

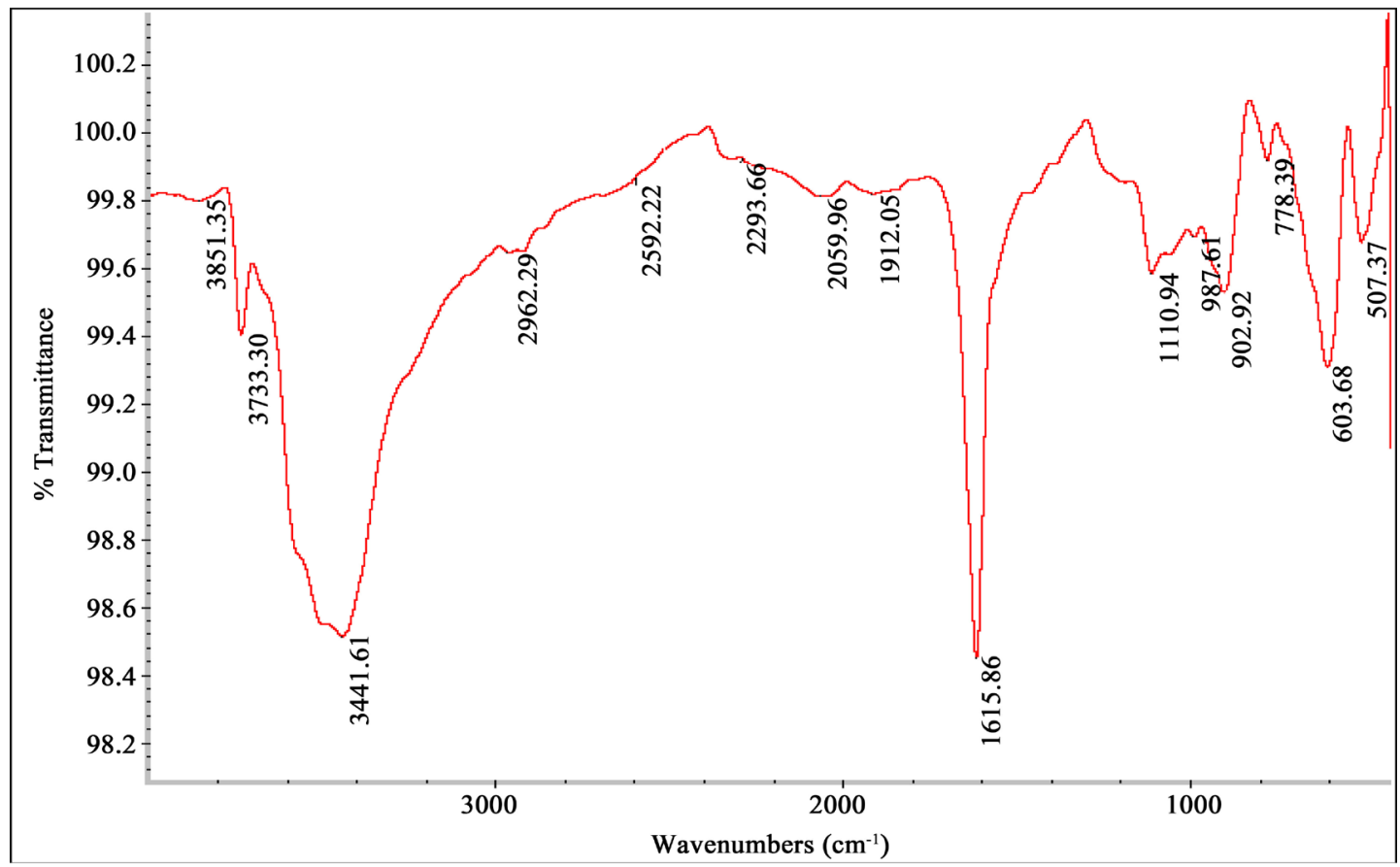

(b)

Figure 2. (a) FTIR spectrum of raw rice straw and, (b) Activated carbon combined with $\mathrm{H}_{3} \mathrm{PO}_{4}$. 


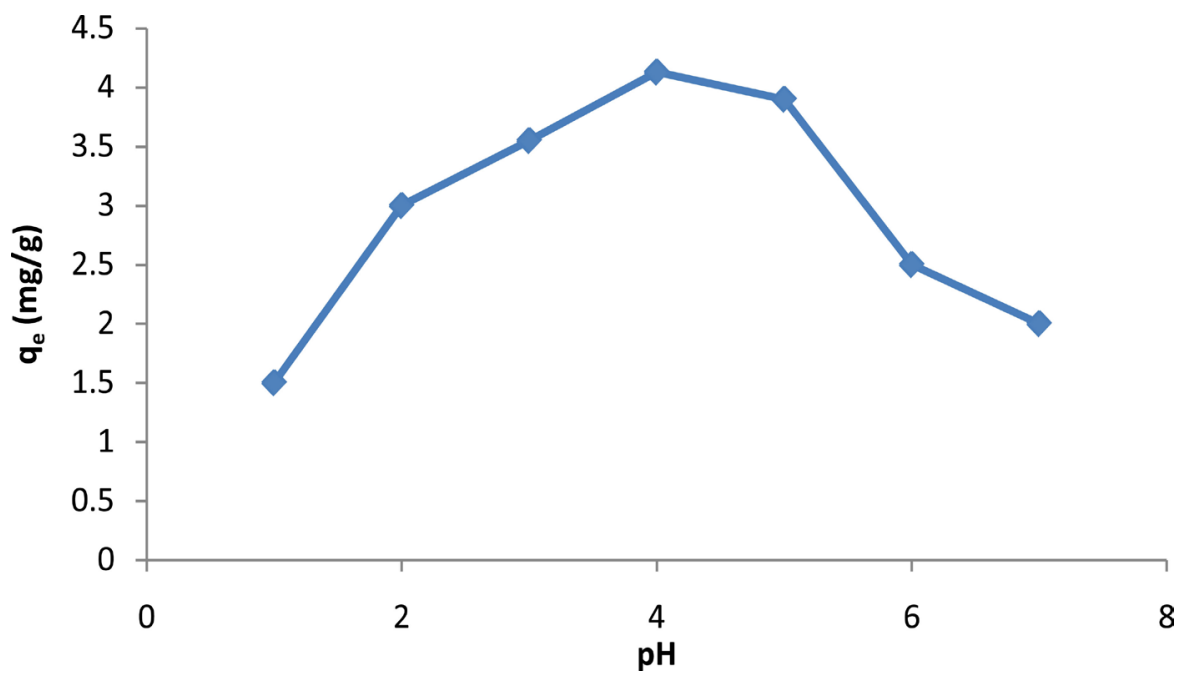

Figure 3. The effect of solution $\mathrm{pH}$ on the cerium adsorption by activated carbon.

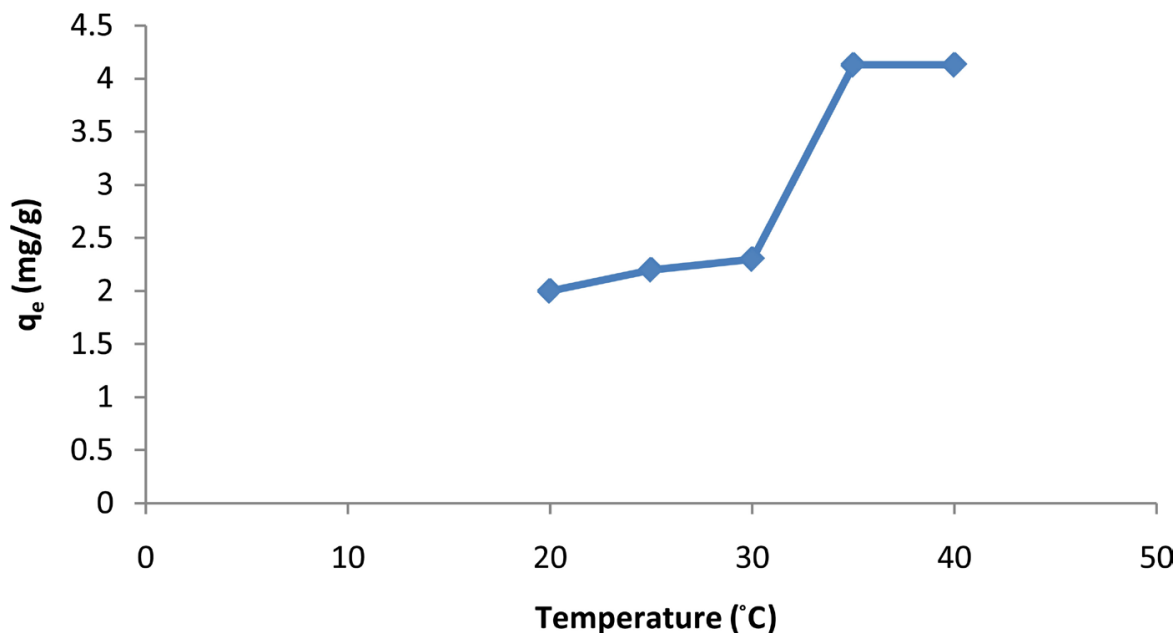

Figure 4. The effect of temperature on the cerium adsorption by activated carbon.

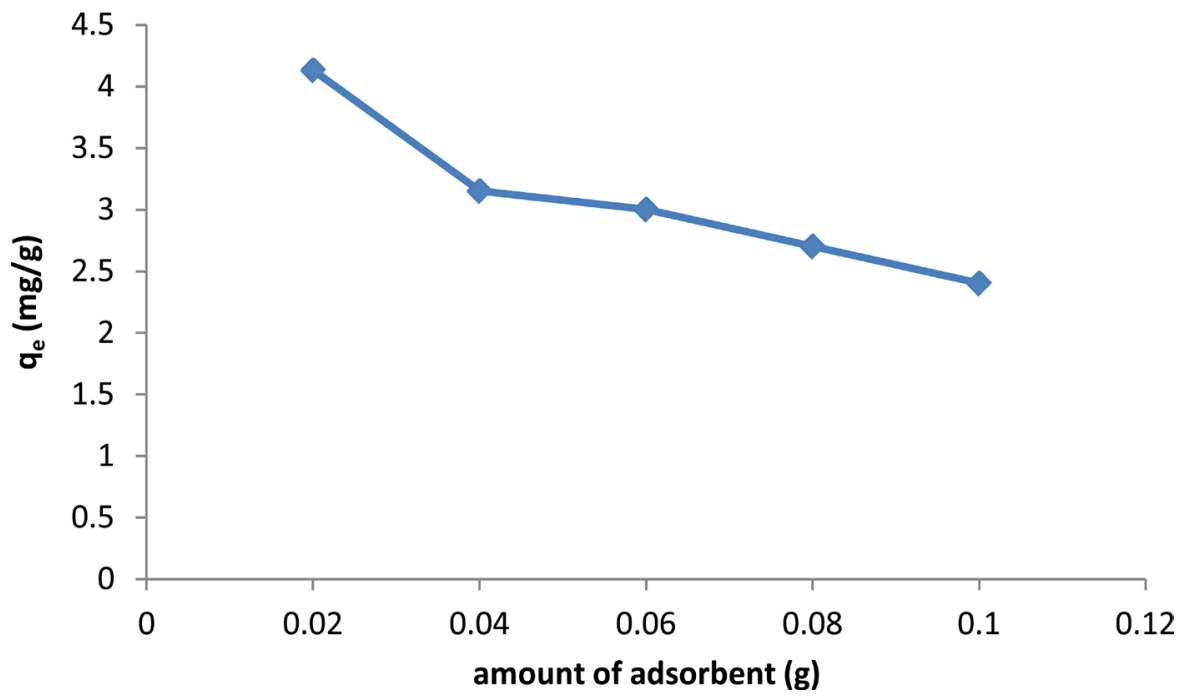

Figure 5. The effects of adsorbent dosage on cerium adsorption by activated carbon. 


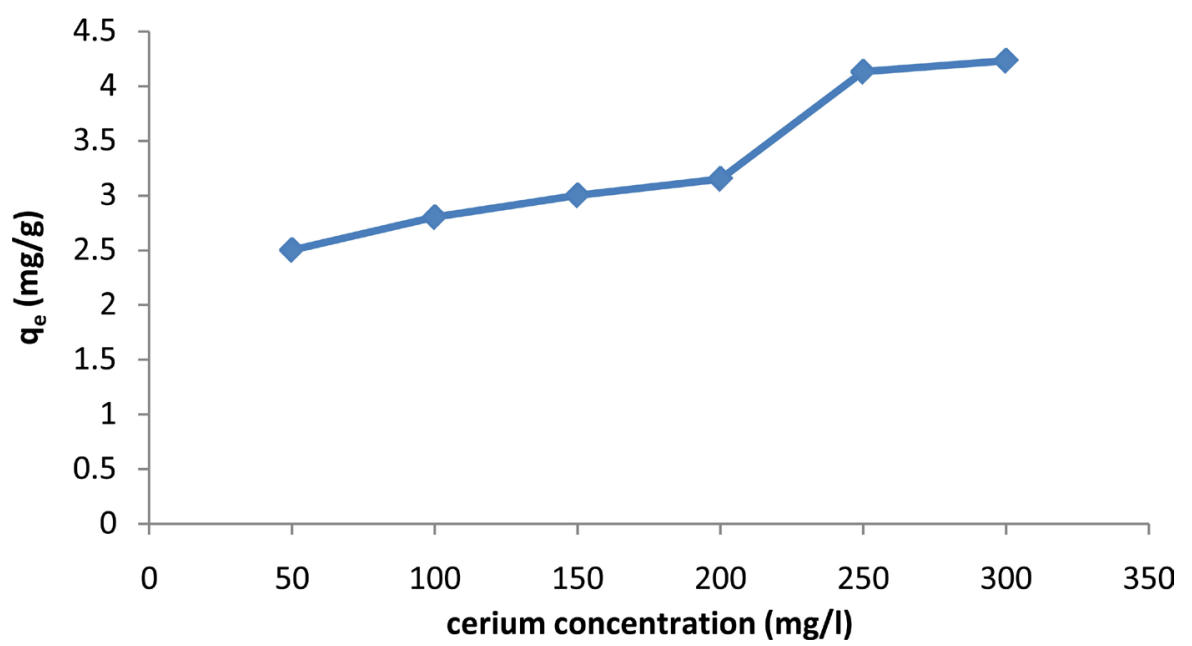

Figure 6. The effects of initial concentration of cerium ions on cerium adsorption by activated carbon.

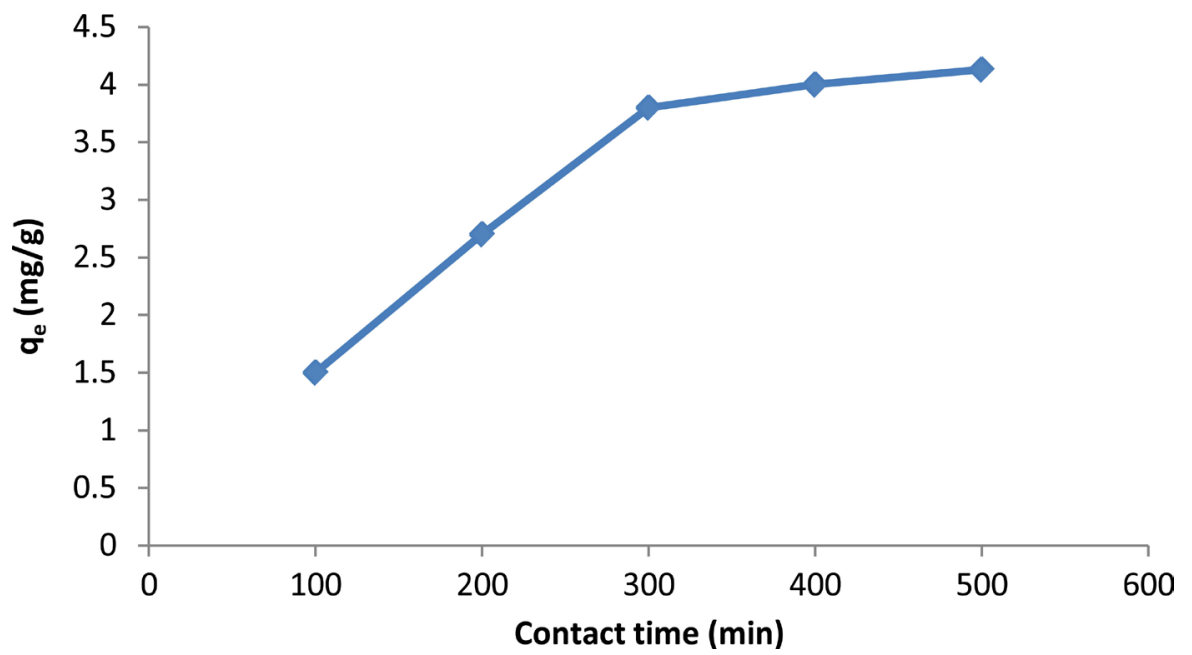

Figure 7. The effect of contact time on the cerium adsorption by activated carbon.

ticipate in metal ion adsorption until the equilibrium is obtained. After equilibrium, there is no significant change in metal ion concentration in the solution.

\section{Results and Discussion}

\subsection{Adsorption Isotherms}

One of the appropriate tools for the thermodynamic and kinetics model of the adsorption process is using different methods to determine the adsorption isotherm. Adsorption isotherm can be expressed in the form of a relationship between the adsorbed concentration onto solid surfaces and contaminant concentrations in solution phase at equilibrium and constant temperature [16]. Adsorption isotherms in laboratory are obtained through tests of the batch system [17] [18]. The results for the adsorption of cerium ions are based on experimental data obtained by the adsorption models of Langmuir and Freundlich and Temkin [19] [20].

\subsubsection{Langmuir Isotherm}

Langmuir model is proposed on the assumption that energy of adsorption is the same in all places. In other words, adsorbent has homogenous surfaces and adsorption occurs in certain places and adsorbed molecules and ions have no interaction effect on each other. Moreover, the maximum adsorption is in the form of monolayer [21] [22]. Langmuir model is described by the following equation: 


$$
\frac{C_{e}}{q_{e}}=\frac{1}{Q_{\max } b}+\frac{C_{e}}{Q_{\max }}
$$

where $C_{e}$ is the concentration of Cerium at equilibrium (mg/l), $q_{e}$ is the amount of Cerium adsorption (mg/g), $Q_{\max }$ is monolayer adsorption capacity $(\mathrm{mg} / \mathrm{g})$, and $b$ is parameter related to energy of adsorption $(\mathrm{l} / \mathrm{mg})$. According to the curve of $C_{e}$ based on $C_{e} / q_{e}$, a linear equation is obtained which can calculate the coefficients of $Q_{\max }$ and $b$. Langmuir constants were calculated on the basis of Figure 8 and the results are shown in Table 1.

\subsubsection{Freundlich Isotherm}

Freundlich isotherm was propposed by Freundlich and Custer in 1894 with a completely empirical relationship and was used in the scope of the changes in low concentrations. It implies that the energy decreases with increasing levels [23] [24]. Freundlich model can be expressed by the following equation:

$$
\log q_{e}=\log K_{f}+\frac{1}{n} \log C_{e}
$$

where $K_{f}$ is Freundlich constant and $n$ is adsorption intensity. Freundlich isotherm constants can be achieved by drawing changes of $\log q$ to $\log C_{e}$. As shown in Figure 9, $K_{f}$ is obtained by y-intercept and $1 / n$ is obtained by line slope. The results are presented in Table 1.

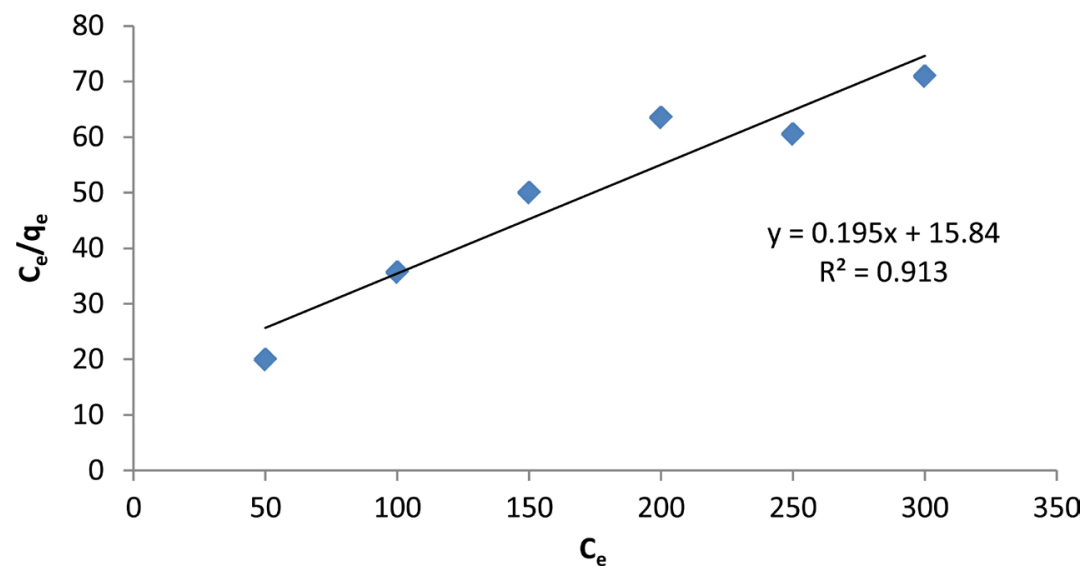

Figure 8. Linear representation of Langmuir adsorption isotherm on cerium ions.

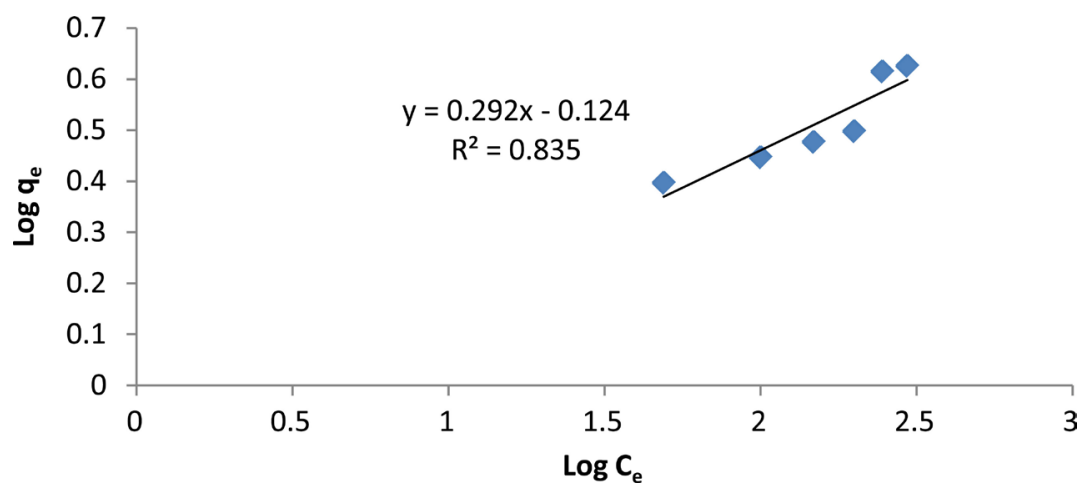

Figure 9. Linear representation of Freundlich adsorption isotherm on cerium ions.

Table 1. Constants obtained for the model of Langmuir, Freundlich and Temkin.

\begin{tabular}{ccccccccc}
\hline & Temkin constant & \multicolumn{3}{c}{ Freundlich constant } & \multicolumn{3}{c}{ Langmuir constant } \\
\hline$B$ & $A$ & $R^{2}$ & $n$ & $K_{f}$ & $R^{2}$ & $b$ & $q_{\max }$ & $R^{2}$ \\
0.95 & 4.67 & 0.78 & 3.42 & 0.9 & 0.83 & 0.012 & 5.12 & 0.91
\end{tabular}




\subsubsection{Temkin Adsorption Isotherm}

Temkin isotherm assumes that the adsorption heat of all molecules in the adsorption layer is linearly reduced. This type of adsorption is characterized by a uniform distribution of bonding energies and is shown as follows:

$$
q_{e}=B \ln A+B \ln C_{e}
$$

where $B$ is Temkin constant related to adsorption heat $(B=R T / b)$ and $A$ is constant of equilibrium bond $(\mathrm{L} / \mathrm{g})$ which is corresponding to maximum binding energy [25] [26]. Temkinisotherm constants can be achieved by drawing changes of $q$ to $\ln C_{e}$ (Figure 10 and Table 1 ).

The results of the adsorption of cerium ion based on the adsorption models of Langmuir, Freundlich and Temkin show that Langmuir equation has a very good correlation coefficient in comparison with the other two equations and it indicates the consistency of the results of this research with Langmuir isotherm.

\subsection{Adsorption Kinetics}

In order to understand the dynamics of adsorption reactions, data on adsorption kinetics were examined.As was observed cerium adsorption increases with increasing time and reaches equilibrium during 300 minutes (Figure 7). The equilibrium time and cerium adsorption depends on the initial concentration of the adsorbed material. In the first stage, adsorption is fast and it gradually declines in the second stage; in other words, the phenomenon of adsorption is under control. The final stage is final equilibrium. There are several mathematical models to describe the reaction kinetics [27]. In this study, we investigated pseudo-first-order model (Lagergren), pseudo-second-order model (Ho et al.), intraparticle diffusion kinetic model and Elovich kinetic model.

\subsubsection{Pseudo-First-Order Kinetics Model}

Pseudo-first-order equation was proposed by Lagergren in 1898 for the adsorption kinetics of the liquid on the solid phase. This model is in line with the adsorption rate based on absorption capacity and is expressed as follows [25] [28] [29]:

$$
\log \left(q_{e}-q_{t}\right)=\log q_{e}-\frac{K_{1}}{2.303} t
$$

where $q_{e}$ is the amount of cerium adsorption (mg/g), $q_{t}$ is adsorption dosage at time of $t(\mathrm{mg} / \mathrm{g}), K_{1}$ is pseudo first-order kinetic constant (1/min), and $t$ is time (min). Pseudo-first-order equation constants can be achieved by drawing changes of $\log \left(q_{e}-q_{t}\right)$ to $t$ (Figure 11 and Table 2).

\subsubsection{Pseudo-Second-Order Kinetics Model}

Pseudo-second-order kinetic model is used to determine the kinetics of absorption based on the absorption capacity of the solution and can be expressed as follows [28] [30] [31]:

$$
\frac{t}{q_{t}}=\frac{1}{K_{2} q_{e}^{2}}+\frac{1}{q_{e}} t
$$

where $q_{e}$ is the amount of cerium adsorption (mg/g), $q_{t}$ is adsorption dosage at time of $t$ (mg/g), $K_{2}$ is pseudo second-order kinetic constant $(1 / \mathrm{min})$, and $t$ is time (min). Pseudo-second-order equation constants can be achieved by drawing changes of $t / q$ to $t$ (Figure 12 and Table 2).

\subsubsection{Intraparticle Diffusion Kinetics Model}

This model is based on the influence of molecules adsorbed to places of the adsorbent in the porosity. Mathematical expression of intraparticle diffusion model is as follows:

$$
q_{t}=K_{p} t^{0.5}+C
$$

where $q_{t}$ is adsorption dosage at time of $t(\mathrm{mg} / \mathrm{g}), K_{p}$ is intraparticle diffusion rate constant $\left((\mathrm{mg} / \mathrm{g}) \cdot \mathrm{min}^{-0.5}\right)$, and $C$ is intraparticle diffusion constant (mg/g) [32]. Intraparticle diffusion constant can be achieved by drawing changes of $q_{t}$ to $t^{0.5}$ (Figure 13 and Table 2).

\subsubsection{Elovich Kinetics Model}

Elovich equation is used to describe the kinetics of absorption and desorption of mineral elements in solid che- 
mistry and can be expressed as follows:

$$
q=\left(\frac{1}{\beta}\right) \ln (\alpha \beta)+\left(\frac{1}{\beta}\right) \ln t
$$

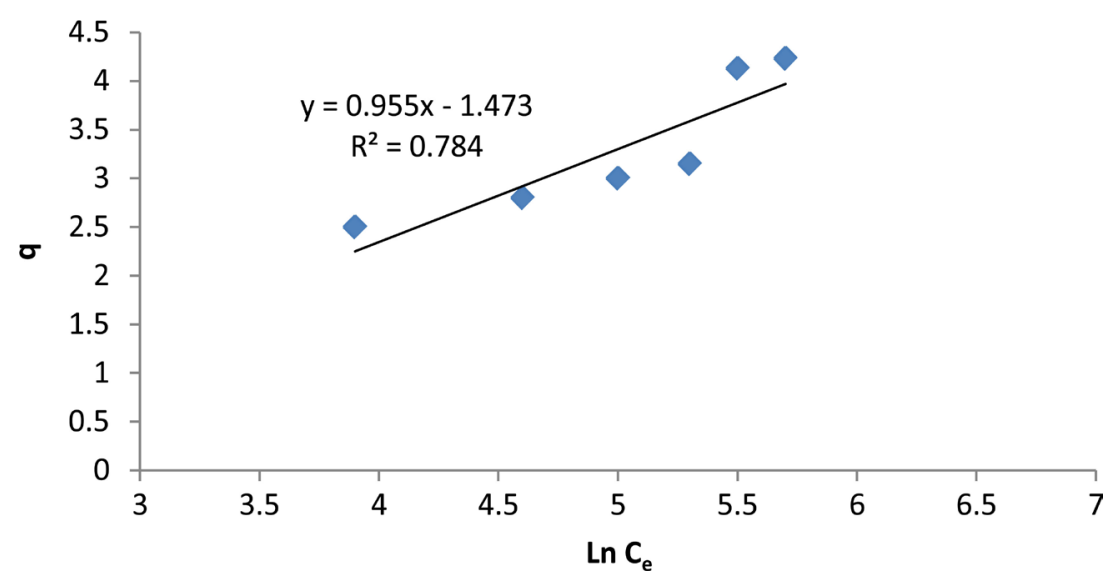

Figure 10. Linear representation of Temkin adsorption isotherm on cerium ions.

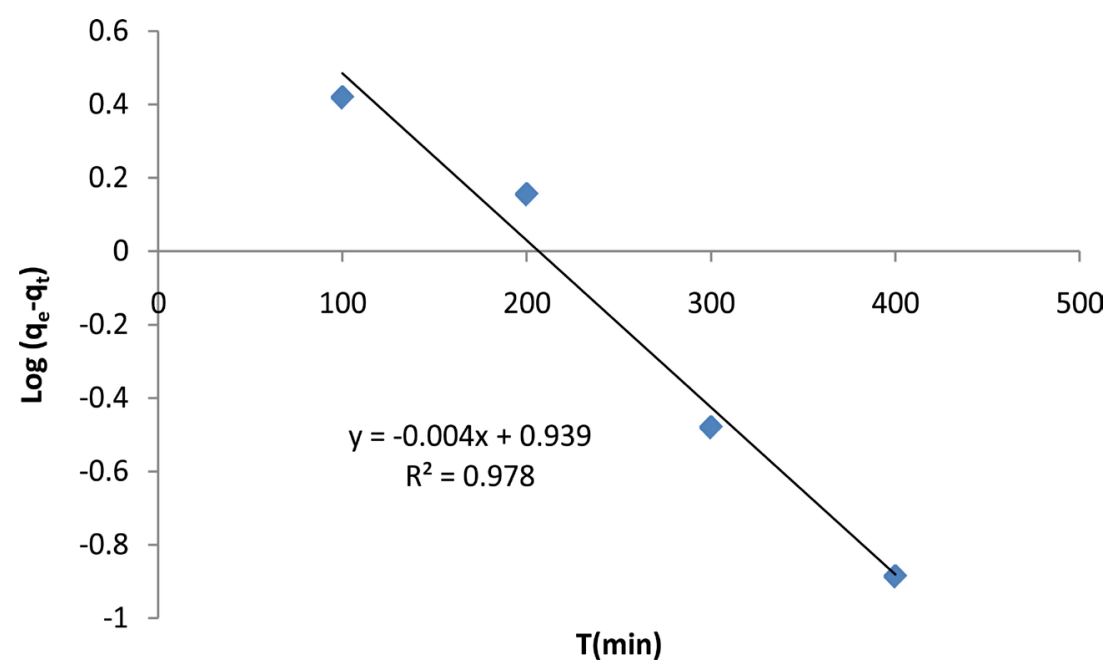

Figure 11. The pseudo-first-order kinetic model (Lagergren’s model).

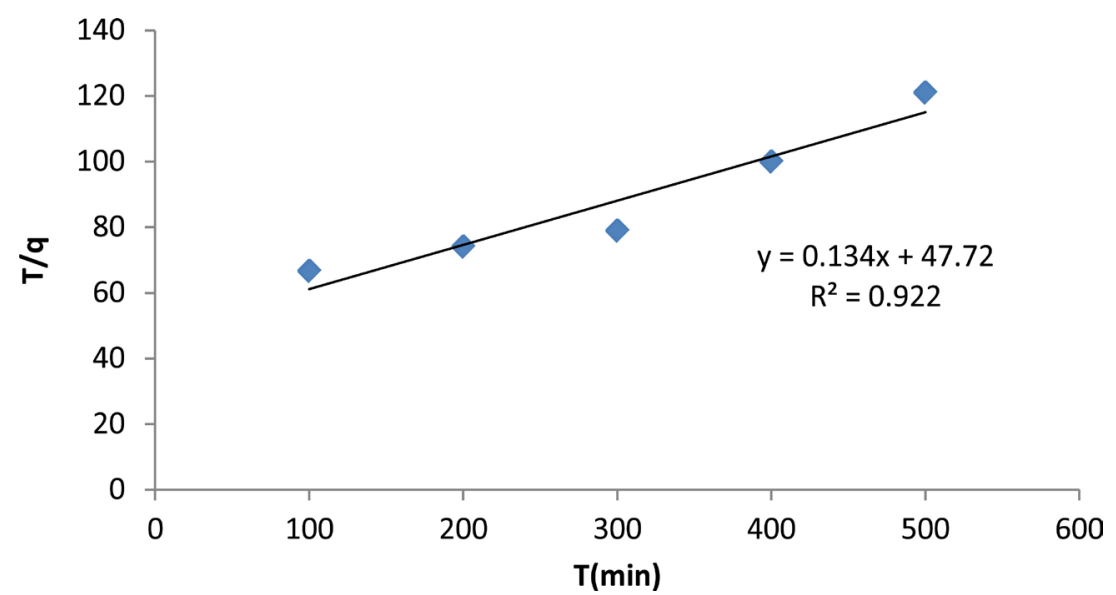

Figure 12. The pseudo-second-order kinetic model (Ho et al.). 


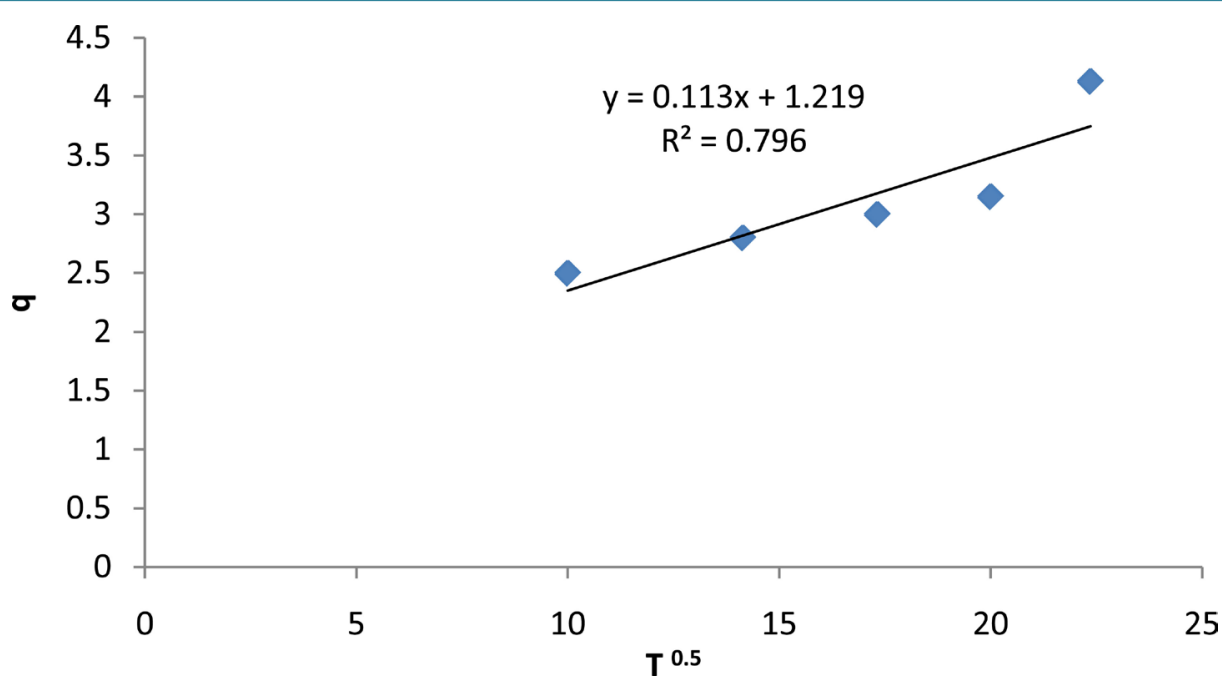

Figure 13. The intraparticle diffusion kinetic model.

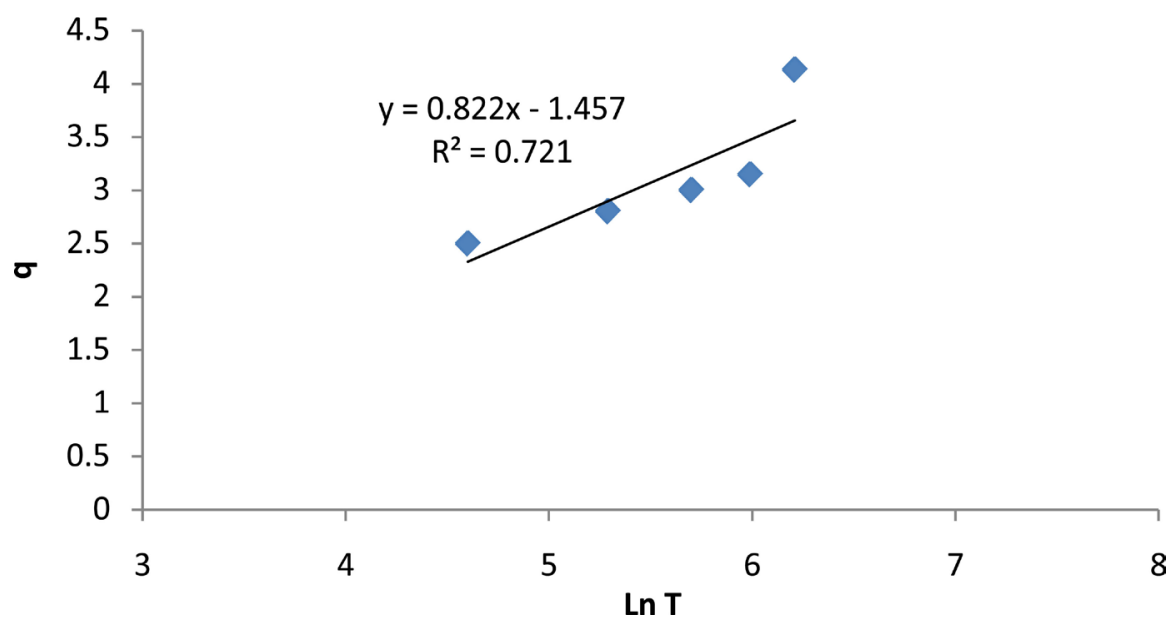

Figure 14. The elovich kinetic model.

Table 2. The calculated constants based on kinetic models of cerium adsorption.

\begin{tabular}{ccccccccccc}
\hline \multicolumn{2}{c}{ Elovich rate constant } & \multicolumn{2}{c}{ Intraparticle diffusion rate constant } & \multicolumn{2}{c}{ Pseudo-second-order rate constant } & \multicolumn{4}{c}{ Pseudo-first-order rate constant } \\
\hline$\alpha$ & $\beta$ & $R^{2}$ & $K_{p}$ & $R^{2}$ & $q_{e}$ & $K_{2}$ & $R^{2}$ & $q_{e}$ & $K_{1}$ & $R^{2}$ \\
0.025 & 1.215 & 0.721 & 0.113 & 0.796 & 7.42 & 0.0012 & 0.922 & 0.94 & 0.01 & 0.978 \\
\hline
\end{tabular}

where $q$ is adsorption dosage at time of $t(\mathrm{mg} / \mathrm{g})$, and $\alpha$ and $\beta$ are constant values during the experiment [33]. Constant values of Elovich equation can be achieved by drawing changes of $q$ to $\ln t$ (Figure 14 and Table 2 ). According to Table 2, analysis of kinetic data on the adsorption process shows that the correlation coefficient for pseudo-first-order kinetic model is higher than the other three models. The pseudo-first-order kinetic model is the most appropriate model for investigation of experimental data on cerium adsorption.

\section{Conclusion}

The results of this study showed that the activated carbon developed from rice straw activated by $\mathrm{H}_{3} \mathrm{PO}_{4}$ was a relatively effective adsorbent for the adsorption of cerium from aqueous solution. The adsorption process obeys Pseudo-first-order kinetic model and Langmuir isotherm model. The highest adsorption of Cerium is determined by $4.13 \mathrm{mg} / \mathrm{g}$ and $\mathrm{pH}=4$. The adsorption dosage increases with increasing the temperature more than $35^{\circ} \mathrm{C}$. In addition, the adsorption dosage has a direct relationship between increasing initial concentration and contact time. 


\section{References}

[1] Franken, K.M. (1995) A Roast-Leach Process for Extraction of Rare Earth from Complex Monazite-Xenotime Concentrates. Separation Science and Technology, 30. http://dx.doi.org/10.1080/01496399508010386

[2] Gschneidner Karl, A. (1964) Rare Earth: The Fraternal Fifteen, U.S. Atomic Energy Commission Division of Techical Information .

[3] Radhika, S., Nagaphani Kumar, B., Lakshmi Kantam, M. and Ramachandra Reddy, B. (2011) Solvent Extraction and Separation of Rare Earths from Phosphoric Acid Solution with TOPS 99. Hydrometallurgy, 110, 50-55. http://dx.doi.org/10.1016/j.hydromet.2011.08.004

[4] Fontana, D. and Pietrelli, L. (2009) Separation of Middle Rare Earths by Solvent Extraction Using 2-Ethylhexylphosphonic Acid Mono-2-Ethylhexyl Ester as an Extractant. Journal of Rare Earths, 27, 830. http://dx.doi.org/10.1016/S1002-0721(08)60344-0

[5] Maleki, A. and Zarasvand, M.A. (2008) Heavy Metals in Selected Edible Vegetables and Estimation of Their Daily Intake in Sanandaj, Iran. Southeast Asian Journal of Tropical Medicine and Public Health, 39, 335-340.

[6] Quintelas, C., Fonseca, B., Silva, B., Figueiredo, H. and Tavares, T. (2009) Treatment of Chromium(VI) Solutions in a Pilot-Scale Bioreactor through a Biofilm of Arthrobacter viscosus Supported on GAC. Bioresource Technology, 100, 220-226. http://dx.doi.org/10.1016/j.biortech.2008.05.010

[7] Sud, D., Mahajan, G. and Kaur, M.P. (2008) Agricultural Waste Mineral as Potential Adsorbent for Sequestering Heavy Metal Ions from Aqueos Solutions: A Review. Bioresource Technology, 99, 6017-6027.

http://dx.doi.org/10.1016/j.biortech.2007.11.064

[8] Dias, J.M. and Alvim-Ferraz, M.C.M. (2007) Waste Materials for Activated Carbon Preparation and Its Use in AqueousPhase Treatment: A Review. Journal of Environmental Management, 85, 833-846. http://dx.doi.org/10.1016/j.jenvman.2007.07.031

[9] Nunes, A.A. and Franca, A.S. (2009) Activated Carbons from Waste Biomass : An Alternativeuse for Biodiesel Production Solid Residues. Bioresource Technology, 100, 1786-1792. http://dx.doi.org/10.1016/j.biortech.2008.09.032

[10] Ahmadpour, A. and Do, D.D. (1997) The Prepration of Activated Carbon from Macadamia Nutshell by Chemical Activation. Carbon, 35, 1723-1732.

[11] Aoyama, M., Tsuda, M., Cho, N.-S. and Doi, S. (2000) Adsorption of Triralent Chromium from Dilute Solution by Conifer Leaves. Wood Science and Technology, 34, 55. http://dx.doi.org/10.1007/s002260050008

[12] Fiol, N., Villaescusa, I., Martinez, M., Miralles, N., Poch, J. and Serarols, J. (2006) Sorption of Pb(II), Ni(II), Cu(II), and Cd(II) from Aqueous Solution by Olive Stone Waste. Separation and Purification Technology, 50, 132. http://dx.doi.org/10.1016/j.seppur.2005.11.016

[13] Panda, G.C., Dasa, S.K., Chatterjee, S., Maity, P.B., Bandopadhyay, T.S. and Guha, A.K. (2006) Adsorption of Cadmium on Husk of Lathyrussativus: Physicochemical Study. Colloids and Surfaces B, 50, 49. http://dx.doi.org/10.1016/j.colsurfb.2006.03.022

[14] Tangaromsuk, J., Pokethitiyook, P., Kruatrachue, M. and Upatham, E.S. (2002) Cadmium Biosorption by Sphingomonas paucimobilis Biomass. Bioresource Technology, 85, 103. http://dx.doi.org/10.1016/S0960-8524(02)00066-4

[15] Gadd, G.M., White, C. and De Rome, L. (1998) Heavy Metal and Radio Nucleotide Uptake by Fungi and Yeasts. In: Norri, R. and Kelly, D.P., Eds., Biohydrometallurgy, Network, Pudvan Publisher.

[16] Monzure Khoda, K. (2009) Adsorption Isotherms. Nanyang Technological University, Nanyang.

[17] Hameed, B.H. (2009) Evaluation of Papaya Seeds as a Novel Non-Conventional Low-Cost Adsorbent for Removal of Methylene Blue. Journal of Hazardous Materials, 162, 939-944. http://dx.doi.org/10.1016/j.jhazmat.2008.05.120

[18] Doulati Ardejani, F., Badii, K., Yousefi Limaee, N., Shafaei, S. and Mirhabibi, A. (2008) Adsorption of Direct Red 80 Dye from Aqueous Solution onto Almond Shells: Effect of pH, Initial Concentration and Shell Type. Journal of Hazardous Materials, 151, 730-737. http://dx.doi.org/10.1016/j.jhazmat.2007.06.048

[19] Langmuir, I. (1918) The Adsorption of Gases on Plane Surface of Glass, Mica and Olatinum. Journal of the American Chemical Society, 40, 1361-1403. http://dx.doi.org/10.1021/ja02242a004

[20] Freundlich, H. (1906) Over the Adsorption in Solution. International Journal of Research in Physical Chemistry and Chemical Physics, 57, 387-470.

[21] Namasivayam, C. and Sangeetha, D. (2008) Application of Coconut Coir Pith for the Removal of Sulfate and Other Anions from Water. Desalination, 219, 1-13. http://dx.doi.org/10.1016/j.desal.2007.03.008

[22] Nemr, A.E. (2009) Potential of Pomegranate Husk Carbon for Cr(VI) Removal from Wastewater: Kinetic and Isotherm Studies. Journal of hazardous Materials, 161, 132-141. http://dx.doi.org/10.1016/j.jhazmat.2008.03.093

[23] Subramanyam, B. and Das, A. (2009) Linearized and Non-Linearized Isotherm Models Comparative Study on Adsorp- 
tion of Aqueous Phenol Solution in Soil. International Journal Environmental Sciences \& Technology, 6, 633-640. http://dx.doi.org/10.1007/BF03326104

[24] Altin, O., Özbelge, H.O. and Dogu, T. (1998) Use of General Purpose Adsorption Isotherms for Heavy Metal-Clay Mineral Interactions. Journal of Colloid and Interface Science, 198, 130-140. http://dx.doi.org/10.1006/jcis.1997.5246

[25] Lagergren, S. (1898) About the Theory of So-Called Adsorption of Solid Substance. Handlinger, 24, 1-39.

[26] Temkin, M. and Pyzhev, J.A.V. (1940) Kinetic of Ammonia Synthesis on Promoted Iron Catalysts. Acta Physicochimica, URSS, 12, 217-229.

[27] Shams Khorramabadi, G., Darvishi Cheshmeh Soltani, R. and Jorfi, S. (2010) Cd(II) Adsorption Using Waste Sludge from a Municipal Wastewater Treatment System. Journal of Water and Wastewater, 1, 57-62.

[28] Qiu, H., Lv, L., Pan, B.C., Zhang, Q., Zhang, W. and Zhang, Q. (2009) Critical Review in Adsorption Kinetic Models. Journal of Zhejiang University SCIENCE A, 10, 716-724. http://dx.doi.org/10.1631/jzus.A0820524

[29] Fan, X., Parker, D.J. and Smith, M.D. (2003) Adsorption Kinetics of fluoride on Low Cost Materials. Water Research, 37, 4929-4937. http://dx.doi.org/10.1016/j.watres.2003.08.014

[30] Ho, Y. (2006) Review of Second-Order Models for Adsorption Systems. Journal of Hazardous Materials, 136, 681-689. http://dx.doi.org/10.1016/j.jhazmat.2005.12.043

[31] Ho, Y.S. and McKay, G. (1998) Sorption of Dye from Aqueous Solution by Peat. Chemical Engineering Journal, 70 , 115-124. http://dx.doi.org/10.1016/S0923-0467(98)00076-1

[32] Wu, J. and Yu, H.Q. (2007) Biosorption of 2,4-Dichlorophenol by Immobilized White-Rot Fungus Phanerochaete chrysosporium from Aqueous Solutions. Bioresource Technology, 98, 253-259. http://dx.doi.org/10.1016/j.biortech.2006.01.018

[33] Sparks, D.L. (1999) Kinetics and Mechanisms of Chemical Reaction at the Soil Mineral/Water Interface. In: Sparks, D.L., Ed., Soil Physical Chemistry, CRC Press, Boca Raton, 135-191. 